\title{
Erratum to: Digitalisation and Service Innovation: The Intermediating Role of Platforms
}

Per Andersson and Lars-Gunnar Mattsson

\section{Erratum to:}

Chapter 8 in: Peter Thilenius et al., Extending the Business Network Approach DOI 10.1057/978-1-137-53765-2_8

Hultén, K., \& Gadde, L.-E. (2007). Understanding the "new" distribution reality through "old" concepts: A renaissance for transvection and sorting. Marketing Theory, 7, 184-207.CrossRef

Hultén, K., \& Mattsson, L. G. (2000). Distribution network dynamics: Evolution in the PC distribution network. The IMP Journal, 4, 170-193.

Changed as

Hulthén, K., \& Gadde, L.-E. (2007). Understanding the "new" distribution reality through "old" concepts: A renaissance for transvection and sorting. Marketing Theory, 7, 184-207.CrossRef

Hulthén, K., \& Mattsson, L. G. (2010). Distribution network dynamics: Evolution in the PC distribution network. The IMP Journal, 4, 170-193.

DOI 10.1057/978-1-137-53765-2_8

P. Andersson . L-G. Mattsson

Stockholm School of Economics, Stockholm, Sweden

(C) The Editor(s) (if applicable) and The Author(s) 2016 